\title{
Mooring System Reliability in Tropical Cyclone and North Sea Winter Storm Environments
}

\author{
Dunja Stanisic $^{\mathrm{a}^{*}}$, Mike Efthymiou ${ }^{\mathrm{a}}$, David J. White ${ }^{\mathrm{b}}$ Mehrdad Kimiaei $^{\mathrm{a}}$ \\ ${ }^{a}$ Centre for Offshore Foundation Systems, The University of Western Australia, Australia \\ b The University of Southampton, UK \\ Email: dunja.stanisic@research.uwa.edu.au; m.efthymiou@shell.com; david.white@soton.ac.uk; \\ mehrdad.kimiaei@uwa.edu.au
}

\begin{abstract}
The characteristics of waves, winds and currents in a tropical cyclone environment differ significantly from those in a winter storm environment, like the North Sea. This can have a significant effect on the reliability of a mooring system that is designed to satisfy $100 \mathrm{yr}$ conditions with specified Factors of Safety in accordance with ISO19901-7 or API RP 2SK. This paper presents reliability analysis of the mooring system of a permanently connected Floating LNG vessel, placed at two locations: (a) a tropical cyclone environment of the North West Shelf of Australia and (b) a winter storm environment of the North Sea. It is demonstrated that as a result of differences in the long term distribution of environmental parameters (waves, winds) between a North Sea environment and a tropical cyclone environment, the long term distribution of the mooring line response differs significantly in these two locations.

This paper shows that a mooring system which is designed in accordance with ISO (or API), in these two environments, will achieve very different reliability levels because of the significant differences in environmental characteristics. In order to achieve the same reliability for the mooring system at these two geographical locations, Factors of Safety for use with $100 \mathrm{yr}$ environmental conditions (Ultimate Limit State) were derived to achieve the same target probability of failure of $10^{-4}$ /annum. It was found that for the North Sea environment, a factor of 1.5 is required for both the mooring chain and the pile, while for the tropical cyclone environment the required Factor of Safety has to be increased to 2.1. These differences are very significant and design standards need to be revised to reflect these findings.
\end{abstract}

\footnotetext{
* Corresponding author. Tel.: (+61 8) 64881142

E-mail address: dunja.stanisic@research.uwa.edu.au (D. Stanisic)
} 


\section{INTRODUCTION}

Floating facilities for oil and gas drilling and production are located in several regions including North Sea (NS), Gulf of Mexico (GoM), West Africa (WA), Brazil, Australia and Southeast (SE) Asia. These regions differ in terms of the magnitude of extreme environmental conditions they experience (e.g. conditions with a return period of 100 years) and also in terms of the long term characteristics of these conditions. For instance, extreme events in the North West Shelf (NWS) of Australia are dominated by tropical cyclones - a rapidly rotating, localised storm system, generating strong winds, waves and surface currents, centred around a low-pressure eye. These cyclonic events with the same features are referred to as hurricanes in the GoM, typhoons in SE Asia and tropical cyclones offshore Australia [1]. In contrast, extreme conditions in the NS and Brazil are dominated by winter storms which tend to have a much larger areal extent than tropical cyclones characterised by low pressure, strong winds and waves. Conditions offshore West Africa tend to be dominated by long period swell. The realisation that different geographical regions exhibit different long term characteristics, with different uncertainties, has been cited in the literature before [2].

Apart from the geographical storm characteristics, the Exposure Level of an installation can be further defined by considering the potential consequences of failure, accounting for potential loss of life, environmental and financial consequences. The highest Exposure Level is that of permanently manned and permanently connected floating installations. Floating systems in the NS, Brazil and West Africa and some major installations recently installed in the NWS of Australia fall in this category. This paper addresses the mooring system design and reliability for this Exposure Level. This is the most important Exposure Level since the consequences of failure are higher and also the majority of installations worldwide fall in this category. This Exposure Level is unfortunately referred to inconsistently in different standards: referred to as Consequence Class 2 in [3], Exposure Level 1 in [4], and Consequence Class 3 in [5] Appendix B.

The reliability of the mooring system is evaluated for two distinct geographical areas, namely the NWS of Australia, where extremes are dominated by tropical cyclones, and NS, where extremes are dominated by winter storms. Recently several permanently manned and permanently moored installations have been installed for the first time in the NWS of Australia in areas with intense cyclonic intensity, namely the Prelude Floating LNG and the Ichthys 
floating installations, and several more are being planned [6]. Hence it is important to understand the reliability of the mooring system of these installations, when designed using the current recommended Factors of Safety (FoS) [5] [7], and to make recommendations specific to this environment if required. Furthermore, it is also important to understand the behaviour of facilities in this environment, what drives this behaviour, and how it compares to an environment like the NS, which is dominated by winter storms.

Recently an extensive study has been carried out by NorMoor Joint Industry Project addressing the mooring reliability of a range of floating facilities in different water depths at two locations: the NS Norwegian continental shelf and the GoM [8], [9], [10]. The study was performed for both the intact condition and the damaged condition. The NorMoor Project developed and recommended FoS for design, which are derived from reliability analysis and are adequate for both locations. Although the NorMoor project is a very comprehensive study, it did not address the mooring reliability of permanently moored vessels in a cyclonic environment.

A previous paper by the authors [11] is complementary to the NorMoor project as it addresses the reliability of the intact mooring chain and pile for a Floating LNG (FLNG), permanently moored in a cyclonic environment of NWS. This previous study showed that higher FoS are required for mooring system design than what is currently recommended in [5]. In this paper the reliability of the same FLNG vessel, placed in the North Sea environment, is evaluated in order to investigate if the requirement for higher FoS arises due to the environmental characteristics, or perhaps the FLNG characteristics or the required target reliability level. This paper extends the previous study and draws conclusions from the relative performance of the mooring system in the two regions. The details of the NS environment are selected to be those of the Norwegian continental shelf that were utilised in the NorMoor Project [8] so as to establish a basis for direct comparison with the NorMoor JIP. A probability of failure is calculated for the mooring chain and the pile, using FoS as currently recommended in ISO [5] and API [7]. A comparison of the results reveals that application of the same design standard leads to a significant difference in calculated reliability of the mooring system for these two environments (tropical cyclone environment of NWS and NS winter storm environment). Because of these differences, the study is extended further to develop different FoS for each location in order to achieve the same target reliability. These new FoS are compared with the current factors recommended by ISO [5]. An additional ALS requirement is introduced, where 
105

106

107

Characteristic Capacity $\geq \gamma($ Characteristic Load Effect $)$

\section{DESIGN PRACTICE} a return period of 10,000yrs and FoS set to unity. laterally loaded pile, are summarised in Table 1.

A permanent mooring system of a floating vessel is generally designed for the Ultimate Limit State (ULS), where the intact system has to withstand environmental conditions with a return period of 100yrs, with a specified FoS. Besides this condition for the ULS, the system should be analysed for a case where one line is missing (the redundancy check). This paper concentrates on the intact ULS condition and the design practice that is applied as per [5]. The API standard [7] has similar recommendations for the intact condition. The Accidental Limit State (ALS) is not required by [5] or [7]. In this paper, an ALS condition is considered as an option, where the intact mooring system is required to survive an environmental condition with

The design checks performed for the ULS as per [5] and [7] utilise a single FoS $(\gamma)$ where:

Characteristic Capacity and Load Effects are defined in subsequent sections. The recommended FoS as per [5] and [7] for the ULS (intact), in application to mooring line and

\section{Table 1- FoS for the mooring line and laterally loaded pile as per [5] and [7]}

\begin{tabular}{ccccc}
\hline $\begin{array}{c}\text { Design } \\
\text { Standard }\end{array}$ & \multicolumn{2}{c}{ Factor of Safety for Mooring } & \multicolumn{2}{c}{ Factor of Safety for Pile } \\
& \multicolumn{2}{c}{ Line } & ALS (intact) & ALS (intact) \\
\hline ISO & 1.67 & Not required & 1.6 & Not required \\
API & 1.67 & Not required & 1.6 & Not required \\
\hline
\end{tabular}




\section{EXTREME ENVIRONMENTAL CONDITIONS}

This paper examines the reliability of the mooring system of the same FLNG vessel, placed in two different environments, one dominated by tropical cyclones (NWS of Australia) and a second one dominated by winter storms (NS). This section presents and discusses the environmental conditions at each of these two environments. To emphasise the differences in long term characteristics of the two environments, the discussion covers extreme conditions with an exceedance probability of $10^{-2}$ annum (return period of 100yrs) and abnormal conditions with an exceedance probability of $10^{-4} /$ annum (return period of $10,000 \mathrm{yrs}$ ). Another aspect which complicates the calculation of extreme responses and the definition of design environmental conditions is that the FLNG is a weathervaning ship-shaped vessel. One consequence of this is that extreme mooring responses occur when winds and waves are not collinear. A second consequence is that wave period $\left(\mathrm{T}_{\mathrm{P}}\right)$ is very important in determining extreme responses, in addition to significant wave height $\left(\mathrm{H}_{\mathrm{s}}\right)$. Hence, responses need to be evaluated over a range of $\left(\mathrm{H}_{\mathrm{S}}, \mathrm{T}_{\mathrm{P}}\right)$ combinations and over a range of travel directions for wind and waves. As a result, the methods used to develop design values of the metocean parameters for extreme event design need to take account of the above.

\subsection{Environment at North West Shelf (NWS) of Western Australia}

The location of the FLNG, considered in this study for the NWS location, is in the most severe region of cyclonic activity off the coast of Western Australia. The environmental conditions, used in this paper, to represent this cyclonic environment in time domain simulations have been derived using the method of joint extremes. The method is applied by Jonathan et al. [12] to develop joint metocean extremes, specific for floating systems, and is based on the model for conditional extremes developed by Heffernan and Tawn [13]. These conditions assume dominancy of one parameter e.g. the significant wave height $\left(\mathrm{H}_{\mathrm{S}}\right)$ and provide values of other parameters which are the most likely values given this dominant parameter. Environmental parameters derived in this manner are dependent on the angle between the environments (e.g. between wind and wave). The derivation of metocean conditions was not performed by the authors and is not the subject of this paper. 
Table 2 summarises four metocean conditions derived using the method of joint extremes. Two relate to the $100 \mathrm{yr}$ return period while the other two correspond to $10,000 \mathrm{yr}$ return period. Condition 1 and Condition 3 result in the largest mooring line loads for $100 \mathrm{yr}$ and $10,000 \mathrm{yr}$ metocean conditions respectively. It can be seen that the ratio between the $\mathrm{H}_{\mathrm{s}}$ that corresponds to $10,000 y r$ (Condition 3 ) and $100 \mathrm{yr}$ return periods (Condition 1 ) is only 1.1. The reason for this is the directionality of winds and waves. In particular, for the 10,000yr condition the angle between the wind and wave is $90^{\circ}$. It is further noted comparing Condition 4 with Condition 2 , (alternative sets of critical conditions) that the ratio between $\mathrm{H}_{\mathrm{S}}$ that corresponds to $10,000 \mathrm{yr}$ $(19.5 \mathrm{~m})$ and $100 \mathrm{yr}$ return periods $(9.0 \mathrm{~m})$ is 2.16 which is much higher than 1.1 . In order to appreciate the true characteristics of the environment and the long term distribution of the significant wave height $\left(\mathrm{H}_{\mathrm{S}}\right)$, the independent conditions for the 100yr and 10,000yr return periods are summarised in Table 3. It can be seen that the ratio of $\mathrm{H}_{\mathrm{s}}$, which corresponds to $10,000 \mathrm{yr}$ and $100 \mathrm{yr}$ return periods, is close to 1.5 .

Table 2- Metocean conditions, derived using the method of joint extremes for NWS location

\begin{tabular}{|c|c|c|c|c|c|}
\hline \multirow{2}{*}{\multicolumn{2}{|c|}{ Environment }} & $100 \mathrm{yr}$ & $100 \mathrm{yr}$ & $10,000 y r$ & $10,000 \mathrm{yr}$ \\
\hline & & Condition 1 & Condition 2 & Condition 3 & Condition 4 \\
\hline \multirow{3}{*}{ Wave } & Spectrum & JONSWAP & JONSWAP & JONSWAP & JONSWAP \\
\hline & $\mathrm{H}_{\mathrm{s}}(\mathrm{m})$ & 12.1 & 9 & 13.4 & 19.5 \\
\hline & $\mathrm{T}_{\mathrm{P}}(\mathrm{s})$ & 14 & 13 & 13.9 & 16.6 \\
\hline \multicolumn{2}{|c|}{$\begin{array}{l}\text { Initial angle of wind relative } \\
\text { to the vessel* }\end{array}$} & $60^{\circ}$ & $-22.5^{\circ}$ & $0^{\circ}$ & $0^{\circ}$ \\
\hline \multicolumn{2}{|c|}{$\begin{array}{l}\text { Angle of wave relative to } \\
\text { wind* }\end{array}$} & $45^{\circ}$ & $67.5^{\circ}$ & $90^{\circ}$ & $0^{\circ}$ \\
\hline \multirow[t]{2}{*}{ Wind } & Spectrum & NPD & NPD & NPD & NPD \\
\hline & $\begin{array}{l}\text { 1hr Mean Speed } \\
(\mathrm{m} / \mathrm{s})\end{array}$ & 34.8 & 29.5 & 37.9 & 42.2 \\
\hline $\begin{array}{l}\text { Curre } \\
\text { nt }\end{array}$ & $\begin{array}{l}\text { Mean Speed }(\mathrm{m} / \mathrm{s}) \\
\text { at } 12 \mathrm{~m} \text { below } \mathrm{MSL}\end{array}$ & 1.2 & 1.2 & 1.2 & 1.3 \\
\hline \multicolumn{2}{|c|}{$\begin{array}{l}\text { Angle of current relative to } \\
\text { wind* }\end{array}$} & $45^{\circ}$ & $67.5^{\circ}$ & $22.5^{\circ}$ & $0^{\circ}$ \\
\hline
\end{tabular}

Another set of design conditions was also utilized which was developed using a response-based approach (see [14] and [15]). This method converts each sea state in the hindcast into a mooring 
165

response. The response-based metocean conditions were used in addition to the conditions derived from joint extremes method in the design of the mooring system presented in this paper. Some further information on the derivation of metocean conditions is given in [16].

Table 3- 100yr and 10,000yr independent metocean conditions for NWS environments

\begin{tabular}{lccc}
\hline $\begin{array}{l}\text { Independent } \\
\text { criteria }\end{array}$ & $100 \mathrm{yr}$ & $10,000 \mathrm{yr}$ & $\begin{array}{l}\text { Ratio } \\
\frac{10,000 \mathrm{yr}}{100 y r}\end{array}$ \\
\hline $\begin{array}{l}\text { 1hr mean wind } \\
\text { speed (m/s) }\end{array}$ & 44.2 & 65.5 & 1.48 \\
$\mathrm{H}_{\mathrm{S}}(\mathrm{m})$ & & & \\
$\mathrm{T}_{\mathrm{P}}(\mathrm{s})$ & 13.7 & 20.7 & 1.51 \\
Current mean & 13.4 & 16.8 & \\
speed at 3m & & & \\
below MSL & & & \\
(m/s) & 1.8 & 2.67 & \\
\hline
\end{tabular}

\subsection{Environment at Haltenbanken in NS}

The location for the FLNG in the NS is chosen to be Haltenbanken on the Norwegian Continental Shelf. This location and the metocean conditions were deliberately selected to be identical to those used in the reliability study performed by NorMoor JIP ([8], [9], [10]) so as to facilitate a direct comparison of the results with those obtained in the NorMoor Project. The metocean criteria are presented in Table 4 and the contour line for $H_{S} v_{S} T_{P}$ is presented in Figure 1. The values used are omnidirectional as done by NorMoor JIP, and follows NS guidance regarding the correlation of winds, waves and currents. It is noted from Table 4 that the ratio of $10,000 \mathrm{yr}$ to $100 \mathrm{yr}$ values of all the metocean parameters is close to 1.2 . This is in sharp contrast to a tropical cyclone environment where this ratio is close to 1.5 (see Table 3).

The sharp difference in the value of this ratio is expected to translate into a sharp difference in 
177 the long term characteristics of mooring response in these two environments. This aspect is demonstrated and discussed further in Section 5 of this paper.

179 For more details on the derivation of the environmental model refer to [8]. Due to the nature 180 of the NS environment, the maximum angle between wave and wind was considered to be $30^{\circ}$, 181 while the maximum angle between wave and current was taken to be $45^{\circ}$. The metocean 182 conditions defined in Table 4 and Figure 1, together with the above qualifications regarding the respective directions were applied to the FLNG vessel in an identical manner as was done in the NorMoor Project so as to maintain consistency. The mooring system was analysed for omnidirectional metocean criteria by considering the omnidirectional contour line and varying the directions of the acting environments also known as environmental contour method. This was done for $100 \mathrm{yr}$ and $10,000 \mathrm{yr}$ return periods and the critical conditions for each were identified. Table 5 presents the critical environmental conditions identified for NS location.

189

Table 4-Independent metocean conditions (omnidirectional) for NS location [8]

\begin{tabular}{cccc}
\hline Metocean Parameter & $100 \mathrm{yr}$ & $10000 \mathrm{yr}$ & Ratio $\frac{10000 \mathrm{yr}}{100 \mathrm{yr}}$ \\
\hline Wind Speed (1-h mean at & 36.0 & 41.6 & 1.16 \\
10m above sea level (m/s) & 16.03 & 20.26 & 1.26 \\
Hs (m) & 1.04 & 1.26 & 1.21 \\
Current speed (m/s) & & & \\
\hline
\end{tabular}

191 


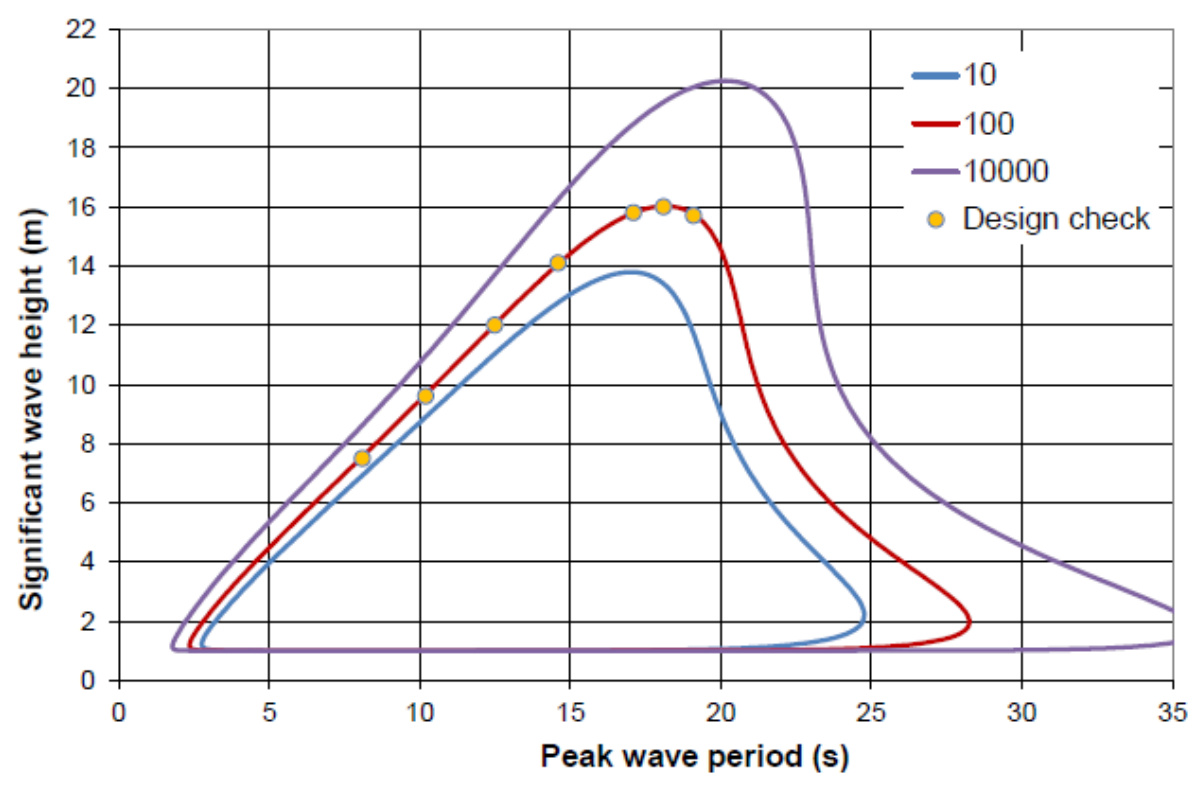

Figure 1- Omnidirectional contour lines of Hs and Tp for NS location [8]

Table 5- Identified critical metocean conditions for tension in mooring line, for NS location

\begin{tabular}{cccc}
\hline \multirow{2}{*}{ Environment } & \multicolumn{2}{c}{ NS Location } \\
\cline { 2 - 3 } & & $100 \mathrm{yr}$ & $10,000 \mathrm{yr}$ \\
\hline Wave & $\mathrm{H}_{\mathrm{S}}(\mathrm{m})$ & 16 & 19.5 \\
& $\mathrm{~T}_{\mathrm{P}}(\mathrm{s})$ & 18 & 18 \\
\hline $\begin{array}{l}\text { Initial angle of wind } \\
\text { relative to the vessel* }\end{array}$ & $0^{\circ}$ & $30^{\circ}$ \\
\hline $\begin{array}{l}\text { Angle of wave relative } \\
\text { to wind* }\end{array}$ & $30^{\circ}$ & $-30^{\circ}$ \\
\hline \multirow{3}{*}{$\begin{array}{l}\text { Spectrum } \\
\text { 1hr Mean }\end{array}$} & NPD & NPD \\
& $\begin{array}{l}\text { Speed } \\
\text { (m/s) }\end{array}$ & 36 & 41.6 \\
\hline Current & $\begin{array}{l}\text { Mean } \\
\text { Speed }\end{array}$ & 1.04 & 1.26 \\
\hline
\end{tabular}




\begin{tabular}{l}
\multicolumn{2}{c}{$(\mathrm{m} / \mathrm{s})$ at the } \\
surface \\
\hline $\begin{array}{l}\text { Angle of current } \\
\text { relative to wind* }\end{array}$ \\
\hline *Positive angle represents clockwise direction
\end{tabular}

*Positive angle represents clockwise direction

\section{FLNG VESSEL AND MOORING SYSTEM CONFIGURATIONS}

200

201

202

203

204

205

206

207

208

209

210

211

212

The vessel considered in this study is a large turret moored FLNG vessel. It is permanently moored in a water depth of 580m in both the NWS and NS locations. The water depth was kept the same at the two locations, in addition to using the same FLNG vessel, so that the differences in results can be attributable to differences in the characteristics of the environment. The mooring system for the FLNG at the NWS comprises 24 catenary mooring lines that are arranged in four bundles, each consisting of 6 lines. This mooring system satisfies the required FoS as per [5] and it is sized such that the lines are approximately fully utilised under $10,000 \mathrm{yr}$ conditions (including short term variability). A total of 14 risers are connected to the vessel through the turret. A fully coupled numerical model has been analysed in the time domain (refer to Figure 2 for the schematic view of the model). The reader can refer to [17] for more details on the model.

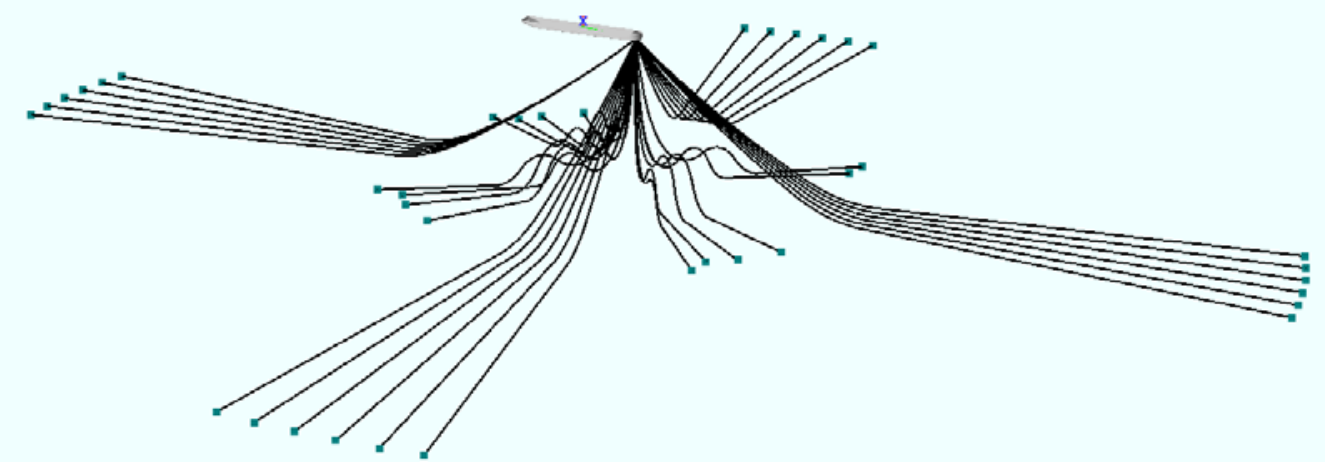

Figure 2- Schematic View of the mooring system and the vessel for NWS environment 
For the NS environment, time domain analyses using the same mooring system revealed that the mooring tension was smaller than what was obtained for NWS environment. Due to the non-linear nature of the mooring response, it is desirable to have comparable utilisations of the mooring lines in these two environments under conditions corresponding to the $10^{-4}$ /annum exceedance level, which corresponds to the target reliability (see Section 6). Hence, for the NS environment, the mooring system was re-designed and reduced to a 16-line mooring system (4 lines in each bundle). As such the most loaded mooring line meets the objective of being fully utilised under 10,000yr conditions, which means that the Most Probable Maximum (MPM) response under 10,000yr conditions (including short term variability) approaches minimum breaking load.

\subsection{Coupled Dynamic Analysis of Mooring System}

The methods of mooring analysis have improved considerably over time, aided also by advances in computing power. Several decades ago the mooring line was analysed on a quasistatic basis by applying motion at the top and analysing the line using catenary equations or a finite element representation. The motion of the floater was estimated separately, by considering the vessel response to the environment and used as input to the mooring analysis in an uncoupled way. Now it is possible to couple the analysis of the vessel motion and the mooring lines into a single system analysed simultaneously. The motion analysis capturing first order, wave frequency motions and second order slow drift motions is carried out in the time domain using a model which includes all the mooring lines and also the risers. Inclusion of the mooring lines and risers ensures that drag forces on these lines, which is an important damping component in the calculation of second order wave drift responses, is correctly incorporated. In the coupled analyses changes in the geometry and stiffness of the mooring lines are modelled explicitly and hence lifting of the mooring line from the sea bed and the impact of this on mass, weight and stiffness, including dynamics, is all captured. Such coupled analyses have been shown to agree well with tests in wave basins and are now regarded as the most accurate tool for mooring analysis [7]. 


\section{CHARACTERISTIC MOORING LINE LOADS AND LONG TERM RESPONSE}

\subsection{Long Term Mooring Response}

The long term distribution for the mooring line response was developed for both the mooring chain and the pile. The method of obtaining the long term distribution accounts for short term variability and is presented in detail in [16] but a summary is provided in this paper, with a focus on the new distributions for the NS environment. The method is presented in terms of the mooring line response, but the same approach is applicable for the pile.

\subsection{Characteristic load}

The characteristic mooring chain and pile load for use in the ULS design check are obtained by carrying out mooring analysis for the design environmental conditions and identifying the most critical conditions (see Table 2 and Table 5 for identified critical conditions for NWS and NS locations respectively). The characteristic load for the chain is taken at the top of the line, at the fairlead, while for the pile the load is recorded at the pile location. The characteristic load for the mooring chain and the pile which is used in ULS check (see Eq. (1)) is the MPM load obtained for the critical environmental condition with a return period of 100yrs (denoted $\mathrm{Y}_{\mathrm{MPM} 100}$ and $\mathrm{Y}_{(\mathrm{P}) \mathrm{MPM} 100}$ for the chain and pile respectively). Similarly, the characteristic load used in the ALS check is the MPM load obtained for the critical environmental condition with a return period of 10,000yrs (denoted $\mathrm{Y}_{\mathrm{MPM10,000}}$ and $\mathrm{Y}_{(\mathrm{P}) \mathrm{MPM} 10,000}$ for the chain and pile respectively). For the 10,000yr condition the lift off of the mooring line at the pile is less than $5^{\circ}$ from horizontal. The small vertical component is resisted directly by the self-weight of the pile and hence, the line of action of the environmental load at the pile can be regarded as horizontal and only the lateral capacity of the pile needs to be considered.

\subsubsection{Long term distribution accounting for short term variability- the approach}

The long term distribution which accounts for short term variability is developed as follows: 


$$
P\left(\frac{Y}{Y_{M P M i}}\right)=\exp \left[-\exp \left(-A\left(\frac{Y}{Y_{M P M i}}-1\right)\right)\right.
$$

The parameter, $\mathrm{A}$, in the above equation is dependent on the magnitude of the mooring response and dictates the breadth of the distribution. Values of parameter, A, derived in this study are summarised in Table 6 for the environment of NWS and NS. It is seen from Table 6 that for the NS environment the values of A are rather close together (17 and 15 for $100 \mathrm{yr}$ and 10,000 yr respectively), whereas for the NWS environment they span a wide range (from 9.5 to 20). 


\begin{tabular}{lcc}
\hline Environment & 100yr return period & $\begin{array}{c}10,000 \mathrm{yr} \text { return } \\
\text { period }\end{array}$ \\
\hline NWS location & 20 & 9.5 \\
NS location & 17 & 15 \\
\hline
\end{tabular}

298

299

300

301

302

$$
P(y>Y)=\int_{0}^{\infty}\left[1-P\left(\frac{Y}{Y_{M P M}} \mid Y_{M P M}\right)\right] \cdot p\left(Y_{M P M}\right) \cdot d Y_{M P M}
$$

303

304

307

d) Convolution- The long term distribution (Eq. (2)) is convoluted with the short term variability (Eq.(3)) to obtain a long term distribution that accounts for short term variability. The convolution can be presented as:

where $\left[1-P\left(\frac{Y}{Y_{M P M}} \mid Y_{M P M}\right)\right]$ is probability that a mooring line response exceeds $\mathrm{Y}$, given that the MPM value of mooring response is $\mathrm{Y}_{\mathrm{MPM}}$ and $p\left(Y_{M P M}\right) \cdot d Y_{M P M}$ is probability interval of getting a mooring response in interval $d Y_{M P M}$.

\subsubsection{Results for Long term distribution for NWS and NS location}

The long term distributions were developed for NWS and NS locations, excluding and including the contribution of the Short Term Variability (STV). These distributions are presented graphically in Figure 3 for the mooring line load. It is clear from the results presented in the figure that the long term distributions at these two locations exhibit different characteristics. The mooring response in the NWS environment has a much steeper distribution, than that of the NS environment. This is further illustrated in Table 7 which presents the mooring responses for the $100 \mathrm{yr}$ and $10,000 \mathrm{yr}$ return periods at both locations. The ratio of the $10,000 \mathrm{yr}$ to $100 \mathrm{yr}$ response, excluding the contribution from short term variability, is 1.95 for the NWS and 1.34 for NS location. These differences can be explained 
327

328

329

330

331

332

by the variation in the long term distribution of the $\mathrm{H}_{\mathrm{S}}$ and wind speed at the two locations (as seen in Table 3 and Table 4 and discussed in Section 3.2). The distribution of $\mathrm{H}_{\mathrm{S}}$ at the NWS location is much steeper than that at NS location. These characteristics of the environment are carried through to the mooring line response distribution of the chain. Similar observations are made for the mooring response recorded at the pile (see Table 8). For the NWS location, the ratio of the $10,000 \mathrm{yr}$ load to $100 \mathrm{yr}$ load at the pile is 2.12 , while for NS this ratio is 1.39 .

\section{Table 7- Characteristics of the mooring chain load long term distribution accounting for short term variability (STV)}

\begin{tabular}{lcccc}
\hline \multirow{2}{*}{ Load description } & \multicolumn{2}{c}{ NWS environment } & \multicolumn{2}{c}{ NS environment } \\
\cline { 2 - 5 } & $100 \mathrm{yr}$ & $10,000 \mathrm{yr}$ & $100 \mathrm{yr}$ & $10,000 \mathrm{yr}$ \\
\hline Load excluding STV $(\mathrm{kN})$ & 7830 & 15290 & 10393 & 13979 \\
$\begin{array}{l}\text { Ratio } \frac{10000 y r}{100 y r} \text { response } \\
\text { Load including STV }(\mathrm{kN})\end{array}$ & \multicolumn{2}{c}{1.95} & \multicolumn{2}{c}{1.34} \\
$\begin{array}{l}\text { Percentage difference when } \\
\text { STV is included }\end{array}$ & 3072 & 16520 & 11096 & 15365 \\
$\begin{array}{l}\text { Equivalent percentile of the } \\
\text { extreme distribution }\end{array}$ & $60^{\text {th }}$ & $60^{\text {th }}$ & $69^{\text {th }}$ & $80^{\text {th }}$ \\
\hline
\end{tabular}

The contribution of STV to the long term distribution of the mooring chain response also differs for the two environments. This contrast can be observed from Table 7 numerically and graphically from Figure 3. For the NWS environment, the 100yr load increases by $3 \%$ when the STV is accounted for, while for the $10,000 \mathrm{yr}$ it increases by $8 \%$. This rise in the load corresponds to moving from the MPM value ( $37^{\text {th }}$ percentile) to the $60^{\text {th }}$ percentile of the extreme mooring load distribution. For the NS environment, the load increases by $7 \%$ and $10 \%$ for the $100 \mathrm{yr}$ and $10,000 \mathrm{yr}$ return periods respectively, when the STV is considered. This load increase is equivalent to $69^{\text {th }}$ and $80^{\text {th }}$ percentile of the extreme mooring line load distribution. The NS environment results get close to the $90^{\text {th }}$ percentile which has been identified in the literature (see [18], [19]) to represent the mooring line load that accounts for STV. For the NWS environment, the percentiles are lower. This further highlights the different nature of the 
tropical cyclone environment. The STV in the NWS environment has a smaller contribution than in the case of the NS environment, due to the steepness of the mooring line response in 341 the NWS environment. The contributions of the STV for the loads recorded at the pile are presented in Table 8 and exhibit very similar behaviour as those of the mooring chain load.
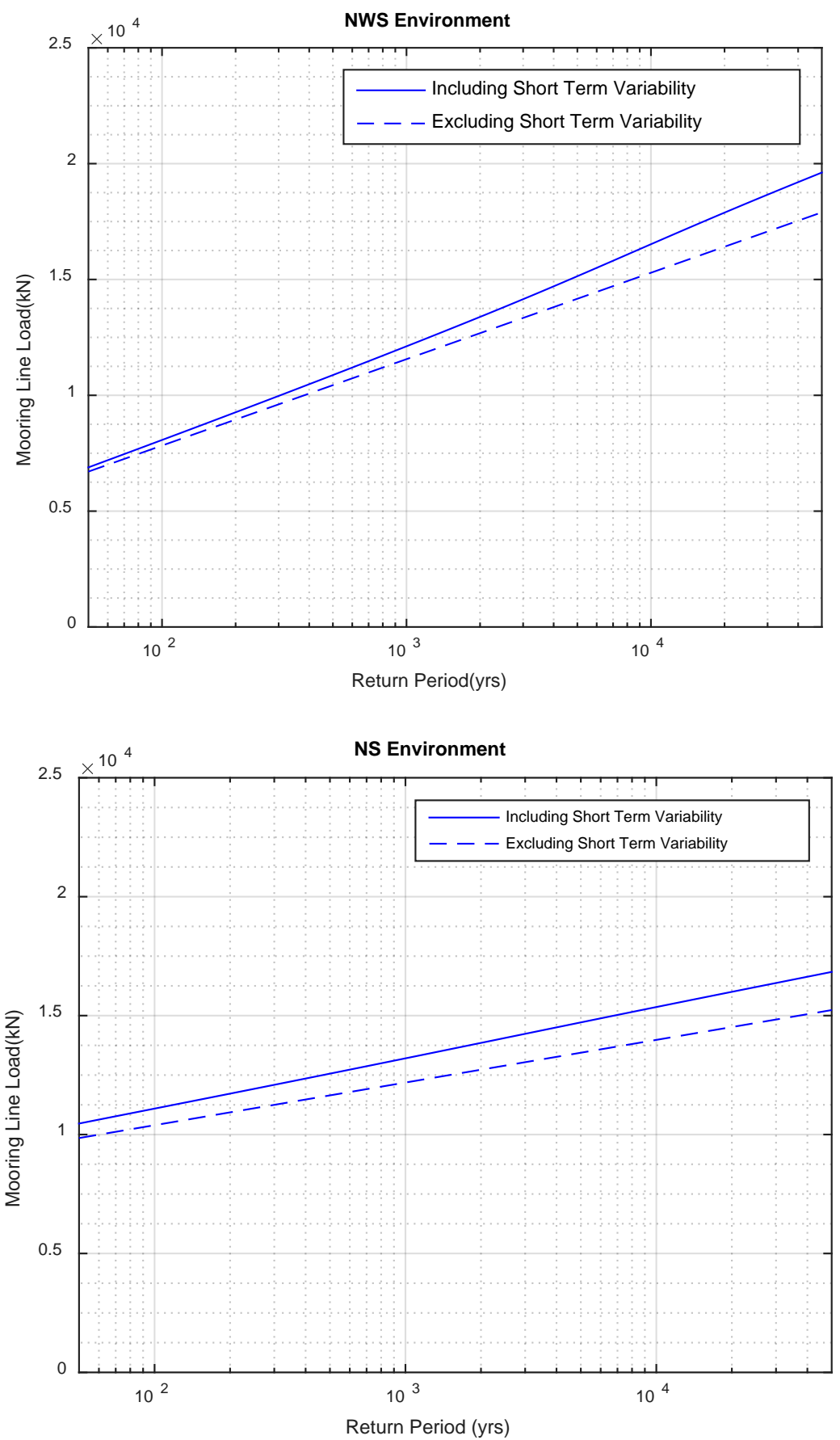

Figure 3- The long term distribution of the mooring line response for NWS and NS 
349

350

351

352

353

354

355

356

357

358

359

360

361

362

363

364

365

366

367

Table 8- Characteristics of the pile load long term distribution accounting for short term variability (STV)

\begin{tabular}{|c|c|c|c|c|}
\hline \multirow[b]{2}{*}{ Load description } & \multicolumn{2}{|c|}{ NWS Environment } & \multicolumn{2}{|c|}{ NS Environment } \\
\hline & $100 \mathrm{yr}$ & $10,000 \mathrm{yr}$ & $100 \mathrm{yr}$ & $10,000 \mathrm{yr}$ \\
\hline Load excluding STV (kN) & 6808 & 14434 & 9432 & 13148 \\
\hline Ratio $\frac{10000 y r}{100 y r}$ response & \multicolumn{2}{|c|}{2.12} & \multicolumn{2}{|c|}{1.39} \\
\hline Load including STV (kN) & 7010 & 15530 & 10035 & 14426 \\
\hline Percentage difference when & & & & \\
\hline STV is included & $3 \%$ & $8 \%$ & $6 \%$ & $10 \%$ \\
\hline $\begin{array}{l}\text { Equivalent percentile of the } \\
\text { extreme distribution }\end{array}$ & $59^{\text {th }}$ & $64^{\text {th }}$ & $70^{\text {th }}$ & $77^{\text {th }}$ \\
\hline
\end{tabular}

\subsubsection{Accounting for modelling uncertainty}

Eq. (4) accounts for natural variability (Type I). Modelling uncertainty (Type II), which arises due to the lack of knowledge, is also considered. In this study three sources of Type II uncertainties are accounted for: i) the modelling uncertainty in estimating MPM, ii) modelling uncertainty in long term methodology and iii) modelling uncertainty due to the derivation of metocean parameters for long return periods. In estimating the above modelling uncertainties, it is taken as a given that the methods of mooring analysis are based on coupled dynamic time domain analyses. The methods of developing design metocean conditions account for the joint occurrence of the metocean parameters including their direction. The total modelling uncertainty due to items i), ii) and iii) was represented with a coefficient of variation (CoV) for $100 \mathrm{yr}$ return period equal to 0.06 and for $10,000 \mathrm{yr}$ return period equal to 0.08 . For more details on how these values were estimated, the reader can refer to [11].

In principle Type II uncertainties can be reduced, however this often involves considerable effort and resources and is not practicable. Instead, in this paper, these uncertainties are accounted for and are introduced into the long term distribution developed in Eq. (4). The variable $Y_{\text {TотAL }}$ incorporates modelling uncertainty and can be obtained using the following expression: 


$$
P\left(y>Y_{\text {TOTAL }}\right)=\int_{0}^{\infty}\left[1-P\left(\frac{Y_{T O T A L}}{Y} \mid Y\right)\right] \cdot p(Y) \cdot d Y
$$

369

370 where, $p(Y)$ is the probability distribution function (derivative) of the long term response 371 obtained from Eq. (4) and $P\left(\frac{Y_{\text {TOTAL }}}{Y} \mid Y\right)$ represents modelling uncertainty which has a Gaussian 372 distribution with $\mathrm{CoV}$ of 0.06 and 0.08 for $100 \mathrm{yr}$ and $10,000 \mathrm{yr}$ return period. The values of $373 \mathrm{CoV}$ between $100 \mathrm{yr}$ and 10,000yr return period are suitably interpolated. A Weibull expression 374 was fitted to the results obtained in Eq. (5), for the mooring chain load at the NS location and $375 p(Y)$ can be written as:

376

$$
p(Y)=-10.77 *\left(\frac{Y}{Y_{M P M 100}}\right)^{1.34} \times e^{\left(-4.61 *{\frac{Y}{Y_{M P M 100}}}^{2.34}\right)}
$$

377

378 For the NWS location expression of $p(Y)$, the reader can refer to [11]. 


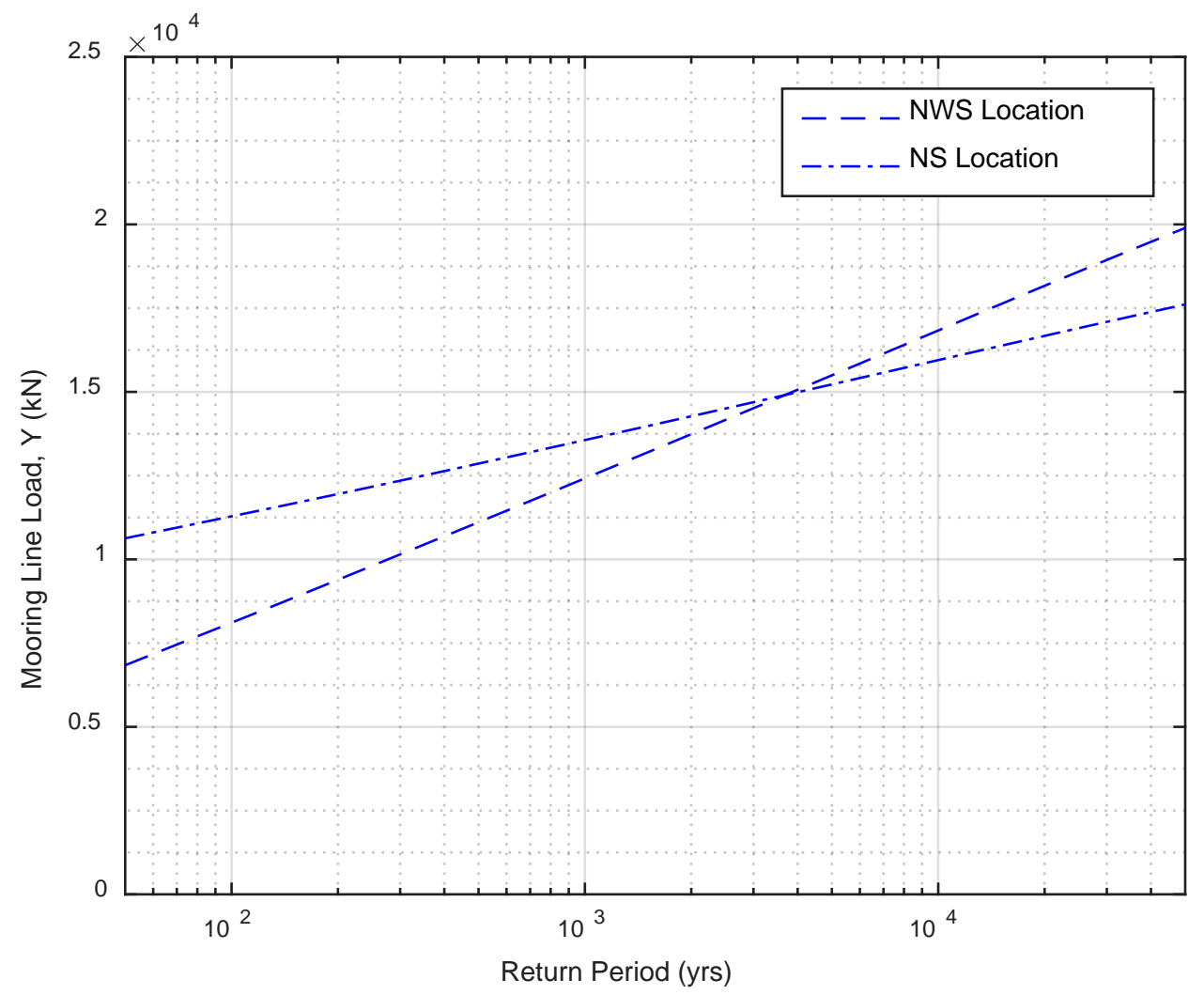

Figure 4-The long term distribution of the mooring line response for NWS and NS environments including for ST variability and modelling error

5.2.4 Long term distribution for NWS and NS which accounts for short term variability and modelling error

386

387 
397 It is a requirement of [5] to allow for mooring chain corrosion and wear. For the mooring chain

408

409

410

Table 9- Mooring chain load long term distribution accounting for short term variability (STV) and modelling error

\begin{tabular}{lcccc}
\hline & \multicolumn{2}{c}{ NWS } & & \\
& \multicolumn{2}{c}{ Environment } & \multicolumn{2}{c}{ NS Environment } \\
& $100 \mathrm{yr}$ & $10,000 \mathrm{yr}$ & $100 \mathrm{yr}$ & $10,000 \mathrm{yr}$ \\
\hline $\begin{array}{l}\text { Mooring load including } \\
\text { STV }\end{array}$ & 8072 & 16520 & 11096 & 15365 \\
Mooring load including & 8110 & 16830 & 11290 & 15954 \\
$\begin{array}{l}\text { STV and modelling error } \\
\text { Percentage change in }\end{array}$ & $0.5 \%$ & $1.9 \%$ & $1.7 \%$ & $3.8 \%$ \\
mooring load & & & & \\
\hline
\end{tabular}

\section{CAPACITY DESCRIPTION}

\subsection{Mooring chain characteristic and stochastic capacity}

The characteristic capacity of the mooring line is the minimum breaking load (MBL) of the mooring chain. This load is specified by the mooring chain manufacturer who performs tests on a line segment that usually comprises of three links (see [20], [21]). The strength of a segment can be taken to be normally distributed with a certain mean and standard deviation. 
416 Based on test results from mooring chains with diameter in the range of $76-120 \mathrm{~mm}$ it was

417

418

419

420

421

422

423 concluded by Stanisic et al. [11] that the mean strength of a chain segment, considered in this study, is $1.07 \mathrm{MBL}$ with a $\mathrm{CoV}$ of 0.025 .

A mooring line can be considered to comprise of $\mathrm{N}$ segments (each segment having 3 chain links) connected in series. The distribution function of the weakest segment $\left(F_{m}\right)$ can be represented by:

$$
F_{m}(y)=1-\left[1-F_{C}(y)\right]^{N}
$$

Where $\mathrm{F}_{\mathrm{C}}$ is the distribution of the strength of one segment. In this paper $\mathrm{N}$ is taken to equal 50 which corresponds to the top 120m length of the line that experiences the maximum load.

\subsection{Pile characteristic capacity}

In the case studied here, the pile is loaded only laterally (see Section 5). As such two failure mechanisms are considered, the short pile failure (soil failure) and the long pile failure (structural failure) [22]. In the short pile failure, the pile is assumed rigid. As the load is applied, the pile rotates about a point which is at distance $\mathrm{z}_{\mathrm{r}}$ below the ground level. The failure occurs in the soil when the applied load exceeds the soil resistance. The long pile failure is the structural failure of the pile, accompanied by failure of the soil causing net pressure on the front of the pile above the hinge point. The pile fails in bending as the plastic hinge forms at $\mathrm{z}_{\mathrm{b}}$ below the ground surface. The two idealised failure mechanisms are presented in Figure 4.

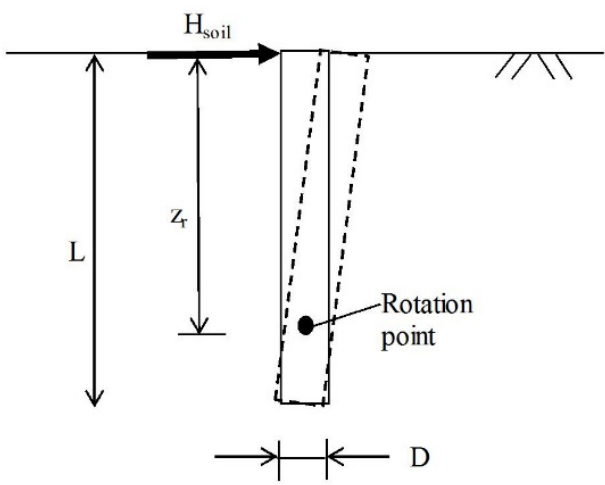

a)

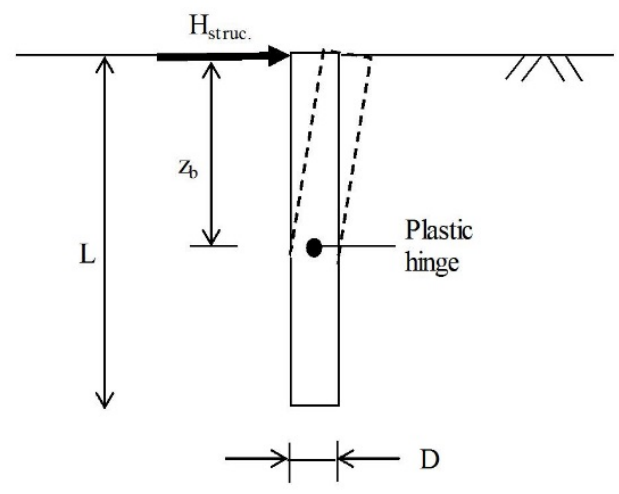

b) 


$$
M_{p}=D^{2} t \sigma_{y}
$$

$$
P=N_{P} \overline{S_{U}} Z D
$$
[11].

The lateral soil resistance is dependent on the pile diameter (D), pile length (L) and undrained shear strength $\left(\mathrm{S}_{\mathrm{U}}\right)$. In this paper the undrained shear strength, with units in $\mathrm{kPa}$ is defined as a linear function of depth below the mudline $(\mathrm{z})$ and can be represented as ( $\left.\mathrm{S}_{\mathrm{UM}}+\mathrm{k}_{\mathrm{SU}} \mathrm{z}\right)$, where $\mathrm{S}_{\mathrm{UM}}$ is the mudline intercept and $\mathrm{ksU}_{\mathrm{SU}}$ is the gradient with depth. As such, the lateral soil resistance on the pile at $\mathrm{z}$ meters below the mudline can be defined as follows:

where $\overline{S_{U}}$ represents the average undrained shear strength over the relevant depth range and Np is the lateral bearing factor taken to be equal to 9 in this study. The plastic pile capacity $M_{P}$ can be represented in terms of the pile steel yield stress $\left(\sigma_{y}\right)$, pile wall thickness $(t)$ and pile diameter (D) as follows:

where $\sigma_{\mathrm{y}}$ is equal to $350 \mathrm{MPa}$. The overall characteristic pile capacity $\left(\mathrm{H}_{\mathrm{ult}}\right)$ is taken to be the minimum of the characteristic pile capacity for the soil failure mechanism $\left(\mathrm{H}_{\text {soil }}\right)$ and the characteristic pile capacity for the structural failure $\left(\mathrm{H}_{\text {struc. }}\right)$ as follows:

$$
H_{u l t}=\min \left(H_{\text {soil },}, H_{\text {struc. }}\right)
$$

For more details on the calculation of the characteristic pile capacities the reader can refer to

Two sets of piles have been designed for each location environment (NWS and NS). The piles are designed for a 100yr load of each environment using a FoS of 1.6, as per Table 1. A lower bound (the $10^{\text {th }}$ percentile) of the characteristic soil undrained shear strength $\left(\mathrm{S}_{\mathrm{U} 10}\right)$, which is given as $\mathrm{S}_{\mathrm{U}}=4+1.63 \mathrm{z}$, was utilised in the design. $\mathrm{S}_{\mathrm{U} 10}$ was used in the design as it was showed that it results in most stable reliability levels [11]. The designed pile characteristics, the characteristic undrained shear strength and design load are presented in Table 10. 
Table 10- Pile properties for NWS and NS environments designed to 100yr factored

\begin{tabular}{cccccc}
\hline Environment & $\mathrm{D}(\mathrm{m})$ & $\mathrm{L}(\mathrm{m})$ & $\mathrm{t}(\mathrm{m})$ & $\begin{array}{c}\text { Factored } \\
\text { Load }(\mathrm{MN})\end{array}$ & $\mathrm{S}_{\mathrm{U} 10}(\mathrm{kPa})$ \\
\hline NWS & 2.5 & 44 & 0.07 & 10.893 & $4+1.63 \mathrm{z}$ \\
NS & 2.9 & 49 & 0.08 & 15.09 & $4+1.63 \mathrm{z}$ \\
\hline
\end{tabular}

462

It is noted that the 100yr pile load in the NS environment is considerably higher than that of the NWS environment and as a consequence the factored load is also higher by the same proportion. This is because the mooring systems in these two environments were sized so as to have similar utilisations under 10,000 year conditions. The driver for this is to achieve similar stiffness characteristics for the mooring lines under conditions close to failure. This has an effect on the time domain analyses and the probability distributions of mooring response. Hence, as expected, the calculated reliabilities and FoS are affected by the stiffness characteristics of the mooring system.

\subsection{Pile stochastic capacity}

472 The main uncertainty in the capacity of the laterally loaded pile comes from the undrained 473 shear strength. The undrained shear strength varies across cone penetration tests (CPT) at the same site and includes spatial variability and variability over depth. It is common practice to choose a certain percentile of the undrained shear strength, most commonly the $10^{\text {th }}$ percentile, as the characteristic value and perform the pile design. The lower bound undrained shear strength considered in this study was derived from CPT data gathered at an offshore site of NWS of Western Australia and is typical for fine grained carbonate soils (e.g. [23, 24]). The lower, best and upper bound of the undrained shear strength are presented in Figure 5. In addition to this soil range, referred to as the base case range, two additional ranges are considered, the narrower and wider range. These ranges are introduced in order to investigate the sensitivity of results to changes in the soil variability. The linear profiles of the $\mathrm{S}_{\mathrm{U} 10}, \mathrm{~S}_{\mathrm{U} 50}$ 
and $\mathrm{S}_{\mathrm{U} 90}$ of these ranges are presented in Table 11, together with the base range. For the two locations considered in this paper, the ranges presented in Table 11 can be considered representative of the range of soil conditions and uncertainty in soil strength for the reliability analysis. This allows a direct comparison of the reliability of the pile due to environmental effects only.

In order to model the variability in undrained shear strength, the gradient $\mathrm{k}_{\mathrm{SU}}$ is taken to be lognormally distributed, with the mudline strength $\left(\mathrm{S}_{\mathrm{UM}}\right)$ directly related to the $\mathrm{ksu}$. The parameters of the lognormal distribution were obtained by fitting the data of each soil strength range considered. The variability in the yield strength is described using the Gumbel distribution with the mean of $1.15 \sigma_{\mathrm{y}}$ and $\mathrm{CoV}$ of 0.05 [25]. The distribution of the pile capacity is obtained by running MonteCarlo simulations and considering the variability described above. More information about the MonteCarlo simulations can be found in [11]. The total distribution of the pile capacity is obtained by picking the minimum of the obtained soil and structural capacity distributions, given that the weaker of the two failure mechanisms will govern in each realisation.

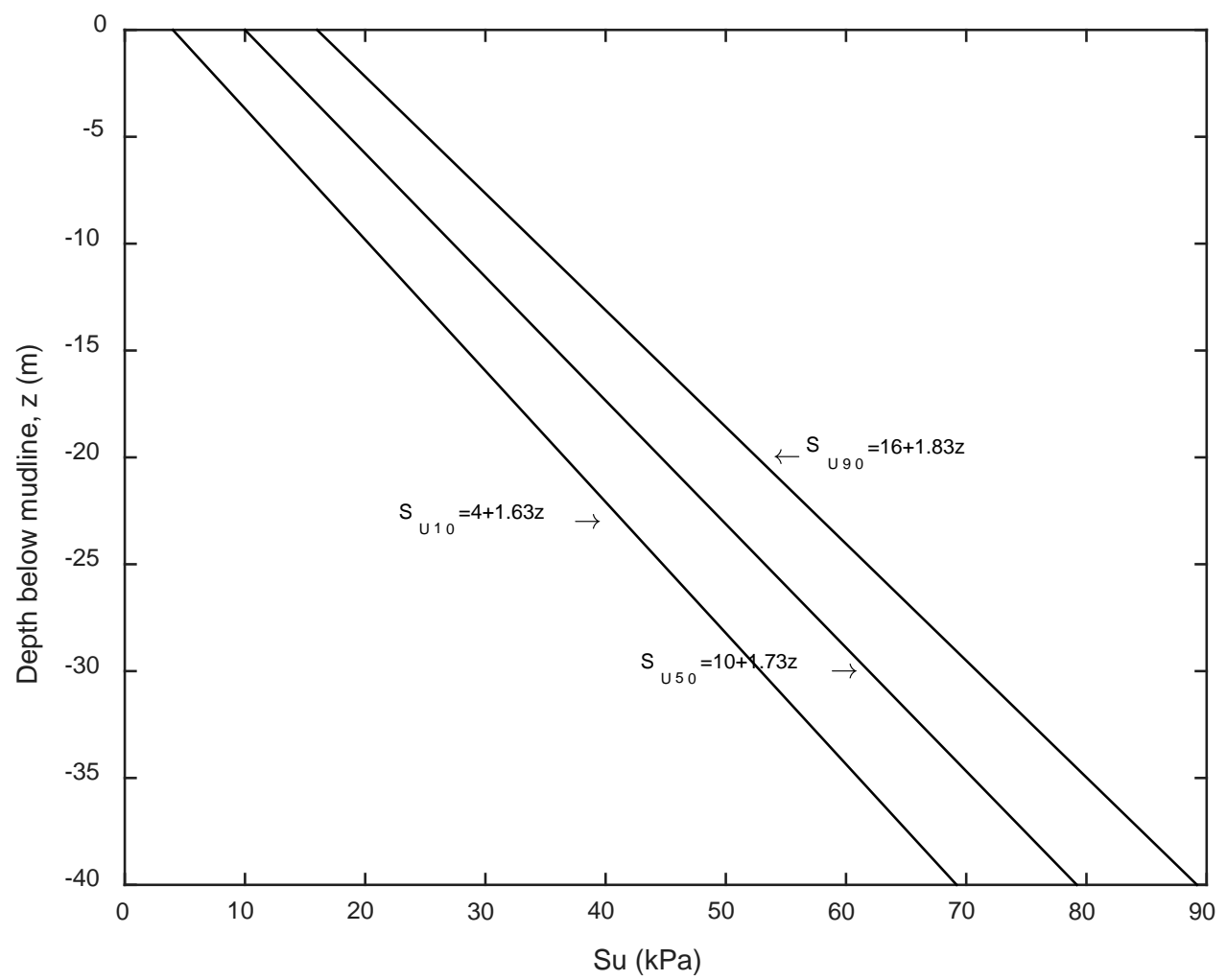

498 


\begin{tabular}{|c|c|c|c|}
\hline Percentile & $\begin{array}{l}\text { Base case range of } \\
\qquad \mathrm{S}_{\mathrm{U}}\end{array}$ & $\begin{array}{l}\text { Narrower Range of } \\
\qquad \mathrm{S}_{\mathrm{U}} \\
\text { Lower natural } \\
\text { variability, or better } \\
\text { characterisation }\end{array}$ & $\begin{array}{c}\text { Wider Range of } \\
\qquad \mathrm{S}_{\mathrm{U}} \\
\text { High natural } \\
\text { variability, or } \\
\text { poorer } \\
\text { characterisation }\end{array}$ \\
\hline $\mathrm{S}_{\mathrm{U} 10}$ (lower bound) & $4+1.63 z$ & $7+1.68 z$ & $1+1.58 \mathrm{z}$ \\
\hline Su50 (best estimate) & $10+1.73 z$ & $10+1.73 z$ & $10+1.73 z$ \\
\hline S u90 $_{\text {(upper bound) }}$ & $16+1.83 z$ & $13+1.78 z$ & $19+1.88 z$ \\
\hline
\end{tabular}

501

502

\section{PROBABILITY OF FAILURE}

503 In Section 5, a probabilistic description of the mooring responses was presented. The 504 description accounts for long term environmental conditions, short term variability and 505 modelling uncertainty. The load is described in terms of a random variable $\mathrm{Y}_{\text {TOTAL }}$ and corresponding cumulative probability distribution $\mathrm{P}\left(\mathrm{Y}_{\text {TOTAL }}\right)$. The stochastic capacity for the mooring chain and the pile was described in Section 6. If the capacity is represented by a random variable (c) and its corresponding probability distribution is $\mathrm{f}_{\mathrm{c}}(\mathrm{c})$, then the probability of failure can be expressed as the probability that the load will exceed the capacity as follows:

$$
p_{f}=P\left(Y_{\text {TOTAL }}>c\right)=\int_{0}^{\infty}\left[1-P_{\text {YTOTAL }}(c)\right] f_{c}(c) d c
$$

511 The probability of failure given by the Eq. (11) is the probability of loss of stationkeeping.

512 Hence, it is the level at which it is meaningful to discuss consequences of failure and therefore 513 targets for mooring reliability or structural reliability. Targets are discussed in Section 7.1 514 below and results from applying Eq. (11) are discussed thereafter. 


\subsection{Target reliability}

516 The mooring lines of a permanently moored and manned vessel are an important design 517 element of the vessel as they prevent loss of stationkeeping, potential loss of life and 518 hydrocarbon spill. Hence, mooring lines are considered to be Safety Critical Elements (SCE).

519 As such, under the regulatory requirements in many countries, the operator is required to 520 demonstrate that the risk for SCE has been reduced to As Low As Reasonably Practicable 521 (ALARP). Such a demonstration is difficult if the FoS in design standards is not related to a 522 reliability target. Recently under the NorMoor Project ([8], [9], [10]) reliability targets were 523 stated. For permanently connected and permanently manned floating systems, the target 524 probability of failure of a mooring system was stated to be $10^{-5} / \mathrm{annum}$. This target was used 525 by NorMoor to develop FoS for permanently manned installations in a NS environment but it 526 was recognised that it is not practicable to achieve such a reliability target in a tropical cyclone environment.

In a recent paper Stanisic et al. [11] applied the principles of Cost-Benefit Analysis to ALARP and concluded that for permanently manned and moored installations in a tropical cyclone environment an appropriate target probability of failure is $10^{-4} /$ annum. This target is used in Section 8 as a basis for developing reliability based FoS for mooring systems in a tropical cyclone environment and a NS environment.

\subsection{Probability of failure for FLNG mooring chain and pile in NWS and NS location}

536 The probabilities of failure for the mooring chain and the pile of the FLNG vessel were 537 evaluated using Eq. (11) for two different locations: the NWS of Australia and NS. The 538 evaluation was performed assuming that each of the critical components (chain or pile) just satisfies the FoS recommended by current standards, as discussed in Section 2. Thus, when using Eq. (11) to calculate $\mathrm{P}_{\mathrm{f}}$ the stochastic capacity of the mooring chain is stated in terms of MBL, e.g. mean segment strength is equal to $1.07 \times \mathrm{MBL}$, where $\mathrm{MBL}$ is not the strength of the selected line size as given by the manufacturer but is given by: 


$$
\begin{gathered}
M B L=F o S \times(\text { Characteristic ULS mooring line response })= \\
1.67 \times(\text { MPM mooring line response under critical 100yr conditions })
\end{gathered}
$$

543 Thus, what is evaluated is not the $\mathrm{P}_{\mathrm{f}}$ of the specific mooring line used in the time domain 544 simulations but the $\mathrm{P}_{\mathrm{f}}$ achieved by the specified FoS for each environment. Table 13 summarises 545 the reliability model, while Table 12 shows the link to the deterministic design process.

Table 12- ULS representation summary

\begin{tabular}{lc}
\hline \multicolumn{1}{c}{ Variable } & Representation \\
\hline Characteristic Response & 100yr MPM \\
Characteristic Capacity & MBL \\
FoS & 1.67 \\
\hline
\end{tabular}

Table 13- Reliability model representation summary

\begin{tabular}{ll}
\hline & \multicolumn{2}{c}{ Most Probable Value } & \\
\cline { 2 - 4 } & Initial distribution has the same Gumbel distribution for \\
MPM as the characteristic response initial distribution is & is \\
Stochastic Loading & at $100 y$ level given in Table 12. modified, as accounted by \\
& Subsequently, the distribution is STV and further modified for \\
& modified to account for STV and modelling \\
& modified again to account for through \\
& modelling error.*
\end{tabular}

\section{Mean Value}

\begin{tabular}{|c|c|c|c|}
\hline \multirow[t]{2}{*}{ Stochastic Capacity } & Single Segment & 1.07 & 0.025 \\
\hline & Line & 1.019 & 0.012 \\
\hline
\end{tabular}

Scatter CoV

*Final MPM increases from $7830 \mathrm{kN}$ (excluding STV) to $8072 \mathrm{kN}$ (including STV) and further increases to 8110 
551 The obtained probabilities of failure for the mooring chain and pile are presented in Table 14.

552 For the pile, besides the base case soil range (as presented in Figure 5) two other ranges are 553 considered: one for wider and one for a narrower variability range (as in Table 11). This is 554 done to investigate the sensitivity of the results to different variability in the soil. When the pile 555 is designed using $\mathrm{S}_{\mathrm{U} 10}$ as the characteristic strength, the obtained probabilities of failure are of 556 similar magnitude, regardless of the variability range. Only for the NS location, the probability 557 of failure does increase somewhat for the wider range. The probability of failure achieved by 558 the mooring chain is very close to that of the pile for both environmental locations.

559 It is seen from Table 14 that the probabilities of failure for the NS environment are considerably 560 lower than those for the NWS environment (34 times lower for the mooring chain and 21 times 561 lower for the pile designed for the base soil range). The mooring chain and the piles for the 562 NWS do not meet the target probability of failure of $10^{-4}$ /annum, while the target is met for the 563 NS environment. As the mooring line strength and pile capacity models used for the two 564 environmental locations are the same, the difference in reliabilities is attributed to the different 565 characteristics of load distribution in these two environments. The load distribution for the NS 566 location has a more gradual increase with return period than that of the NWS location, resulting 567 in lower probabilities of failure for a mooring system which is designed to satisfy specified 568 FoS under 100yr conditions. designed to 19901-7 FoS

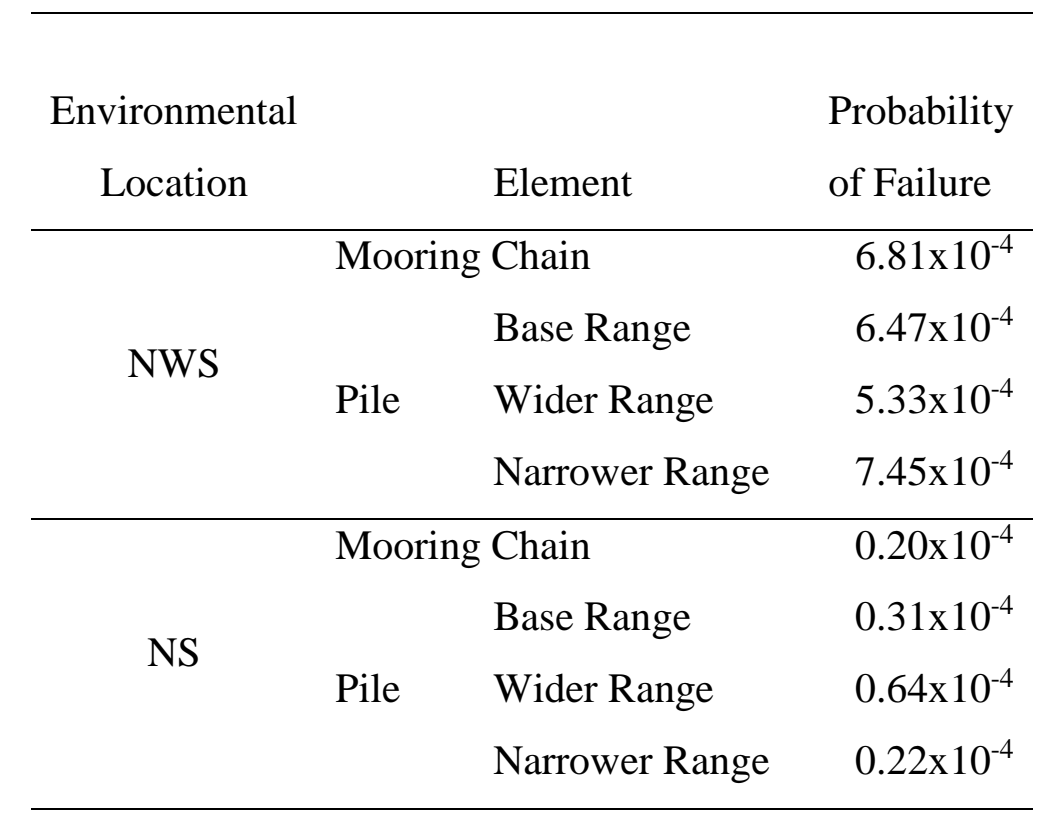




\section{RECOMMENDED FOS FOR MOORING CHAIN AND PILE TO ACHIEVE TARGET RELIABILITY OF 10-4/ANNUM}

With the objective of achieving uniform reliability levels across different geographical locations, the FoS required to meet the target probability of failure of $10^{-4}$ /annum, were calculated for the mooring chain and the piles in each of the two environments - tropical cyclone in NWS of Australia and winter storm environment of the NS - and using the characteristic soil strength of $\mathrm{S}_{\mathrm{U} 10}$. The factors are presented in

Table 15. It can be observed that for the NWS the required FoS of 2.1 is larger than the [5] recommended factor of 1.67 for the chain and the 1.6 for the laterally loaded pile. For the NS environment (as expected based on Table 14) the required FoS is 1.5, if the values in

Table $\mathbf{1 5}$ are rounded to one decimal place.This value is lower than the ISO recommended FoS. It is noted that for the piles the required FoS is the same for a given environment when $\mathrm{S}_{\mathrm{U} 10}$ is used for the characteristic soil strength in the pile design. This is convenient and it means that the FoS does not need to vary depending on the soil variability range as long as $\mathrm{S}_{\mathrm{U} 10}$ is selected for characteristic soil strength. This observation is consistent with the commentary in Appendix D of [26] which notes that low fractiles of soil strength are favoured as a characteristic design input since the reliability is then less dependent on the adopted partial or global FoS. The results presented in this Section highlight that the required FoS for a tropical cyclone environment (2.1) is considerably higher than the corresponding FoS for a NS winter storm environment (1.5) and design standards need to account for this difference.

Three further questions relating to mooring system reliability are:

(i) Is the target reliability level of $10^{-4}$ /annum adequately achieved by introducing an ALS design provision for the intact mooring system?

(ii) Is a target reliability level of $10^{-4}$ /annum justified for the NS environment based on ALARP considerations?

(iii) What FoS is needed to achieve a target reliability level of $10^{-5} /$ annum for a NS environment?

These questions are addressed in Section 9 below. 
Table 15- FoS required for NWS and NS environments to achieve target reliability

under ULS condition

\begin{tabular}{|c|c|c|c|}
\hline Location & & Element & $\begin{array}{c}\text { Factor of } \\
\text { Safety }\end{array}$ \\
\hline \multirow{4}{*}{ NWS } & \multicolumn{2}{|c|}{ Mooring Chain } & 2.1 \\
\hline & & Base Range & 2.1 \\
\hline & \multirow[t]{2}{*}{ Pile } & Wider Range & 2.1 \\
\hline & & Narrower Range & 2.1 \\
\hline \multicolumn{3}{|c|}{ Mooring Chain } & 1.54 \\
\hline \multirow{3}{*}{ NS } & \multirow{3}{*}{ Pile } & Base Range & 1.47 \\
\hline & & Wider Range & 1.54 \\
\hline & & Narrower Range & 1.45 \\
\hline
\end{tabular}

602

\section{ADDITIONAL MOORING SYSTEM RELIABILITY STUDIES}

\subsection{Additional ALS design requirement}

605

606

607

608

609

610

611

612

613

614

615

616

617

The question addressed here is whether the target reliability level of $10^{-4}$ /annum can be adequately achieved by introducing an ALS design provision requiring the mooring system to satisfy environmental conditions with exceedance probability of $10^{-4} / \mathrm{annum}$ and FoS set to unity. In this design check, the characteristic values of capacity remain the same as defined in Section 7, namely:

- Chain characteristic strength is the Minimum Breaking Load, MBL (as per Eq. (12))

- Soil characteristic strength is the $10^{\text {th }}$ percentile of undrained shear strength, $\mathrm{S}_{\mathrm{U} 10}$

The characteristic value of response is the MPM response under environmental conditions with a return period of 10,000yrs. Table 16 presents the probabilities of failure for the mooring chain and pile analysed for NWS and NS environment under this ALS condition. It is seen that introducing this ALS requirement for the tropical cyclone environment leads to $\mathrm{P}_{\mathrm{f}}$ of $2.0 \times 10^{-}$ 4/annum for the mooring chain and $\mathrm{P}_{\mathrm{f}}$ of $0.8 \times 10^{-4} / \mathrm{annum}$ for the pile. Thus the target of $10^{-}$ 4/annum is met for the pile but it is not met for the chain. For the NS environment, the 
probabilities of failure are even larger with $\mathrm{P}_{\mathrm{f}}$ of $6.2 \times 10^{-4} /$ annum for the mooring chain and $\mathrm{P}_{\mathrm{f}}=2.0 \times 10^{-4} /$ annum for the pile. Thus the target $\mathrm{P}_{\mathrm{f}}$ is not met for the chain or the pile. Hence, simply introducing an ALS provision, (on its own) as discussed above, does not achieve the target $\mathrm{P}_{\mathrm{f}}$, especially for the NS environment. This is because the slope of NS is mild and the contributions from short tern variability become more pronounced (see Figure 3). It can be observed that the response at the return period of 10,000yr, excluding the short term variability, corresponds to a return period of about 3,000yr, when viewed including the short term variability. If, however, the ALS provision is introduced in addition to the ULS provision with FoS as presented in this paper, then the ALS provision may serve a useful purpose as a safeguard for applications which are step outs in terms of system responses or environmental conditions.

\section{Table 16- Probabilities of failure achieved for NWS and NS under introduced ALS} condition

\begin{tabular}{ccc}
\hline Location & Element & $\begin{array}{c}\text { Probability of } \\
\text { Failure }\end{array}$ \\
\hline \multirow{2}{*}{ NWS } & Mooring Chain & $2.0 \times 10^{-4}$ \\
& Pile* & $0.8 \times 10^{-4}$ \\
\multirow{2}{*}{ NS } & Mooring Chain & $6.2 \times 10^{-4}$ \\
& Pile* & $2.0 \times 10^{-4}$ \\
\hline & *Based on pile designed to $S_{U 10}$
\end{tabular}

\subsection{Target reliability for NS environment}

In Stanisic et al. [11] cost-benefit analysis and ALARP considerations were used to demonstrate that a target reliability of $10^{-4}$ /annum is appropriate for the mooring system of a major installation in a tropical cyclone environment. This evaluation makes use of the incremental cost of improving safety. Since the slope of the long term mooring response in a NS environment is considerably lower, it follows that the incremental cost of improving safety by a specified factor is lower in a NS environment. This is illustrated in Figure 6 which shows the incremental cost of improving safety and total system costs for NS and NWS environments. 
642 It is seen from Figure 6 that the minimum total cost for the NS, corresponds to a reliability 643 level of about $1 \times 10^{-4} /$ annum. Hence, it can be concluded that the suitable target reliability for 644 NS environment is also $10^{-4}$ /annum.

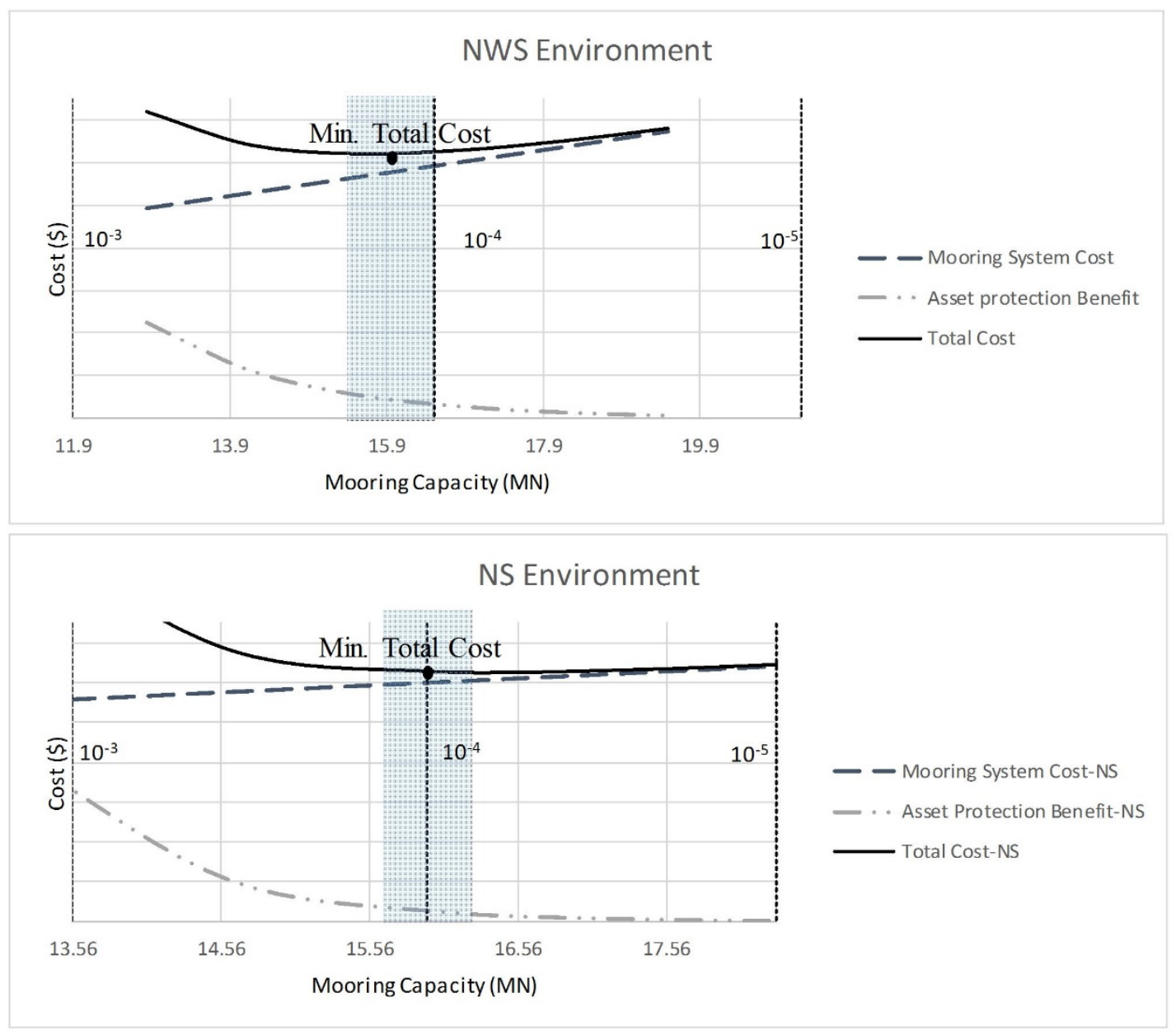

645

Figure 7- Cost Benefit Analysis for NWS and NS environment

\subsection{FoS needed to achieve target reliability of $10^{-5}$ /annum for NS} Environment

The FoS required to meet a target $\mathrm{P}_{\mathrm{f}}$ of $10^{-5}$ /annum, were calculated for the mooring chain and the piles for the winter storm environment of the NS. The factors are presented in Table 17. It is seen that the required FoS is 1.8 for the chain and ranges between 1.7 and 1.9 for the pile.

653 This is very similar as the value of 1.9 (about 6\% lower for the chain) developed by the NorMoor Project for the NS environment. This difference can be explained partly by the fact 
that the NorMoor project took into consideration several geographical locations (NS and Brazil) and several vessel types (semisubmersible and FPSO) and the resulting FoS were weighted and rounded upwards. Recognising this, the results obtained in this paper are in very good agreement with those of the NorMoor Project.

\section{Table 17- FoS required for NS environment to achieve target reliability of $10^{-5} /$ annum}

\begin{tabular}{|c|c|c|c|}
\hline Location & & Element & $\begin{array}{l}\text { Factor of } \\
\text { Safety }\end{array}$ \\
\hline \multirow{5}{*}{ NS } & Moori & Chain & 1.8 \\
\hline & \multirow{4}{*}{ Pile* } & Base Range & 1.7 \\
\hline & & Wider Range & 1.9 \\
\hline & & Narrower & \\
\hline & & Range & 1.7 \\
\hline
\end{tabular}

\section{CONCLUSION}

This paper compares reliability analysis of a mooring chain and pile analysed at two different environments: a cyclonic environment on the NWS of Australia and a winter storm environment at the Norwegian continental shelf in the NS. The mooring system is attached to a large FLNG vessel, designed to be permanently moored on location. The permanently moored ship shaped vessels are novel to NWS. Hence, as the experience in floating vessels is greater for NS location, the results obtained for NWS are compared to those obtained for the same vessel analysed for NS environment. This enabled a better understanding of the different characteristics of mooring responses in these two environments.

- It was found that the long term distribution of the wave height in the NWS environment is much steeper than that of the NS, with the ratio of $10,000 \mathrm{yr}$ to $100 \mathrm{yr}$ equal to 1.26 for NS and 1.5 for NWS location.

- The metocean characteristics, at these two locations, are transferred to the long term distribution of the mooring line response. The ratio of $10,000 \mathrm{yr}$ to $100 \mathrm{yr}$ mooring line 
is estimated to be 1.34 for NS but it increases to 1.95 for the tropical cyclone environment of NWS. In addition, in the tropical cyclone environment, the winds change more rapidly and vas consequence larger angles between winds and waves can occur. This has a contribution on the steeper slope As such, the contribution of the short term variability to the long term distribution of the mooring load is much smaller for NWS (3\% and $8 \%$ for $100 \mathrm{yr}$ and $10,000 \mathrm{yr}$ response) than is the case at NS location (7\% and $10 \%$ for $100 \mathrm{yr}$ and $10,000 \mathrm{yr}$ response).

- A mooring system which is designed in accordance with ISO [5] (or API [7]) in these two environments achieves very different reliabilities because of the significant differences in environmental characteristics. For the tropical cyclone environment the probability of failure was found to be 34 times higher for the chain and 21 times higher for the pile when compared to those obtained for a NS environment. These observations are attributed to the different long term response characteristics, which are due to differences in environmental characteristics at these two locations, as everything else is kept constant.

- In order to achieve the same reliability for the mooring system at these two geographical locations, FoS were derived to achieve a target probability of failure of $10^{-4}$ /annum. It was found that for the NS environment, a factor of 1.5 is required for both the mooring chain and the laterally loaded pile, while for the NWS environment the required FoS for both the mooring chain and the pile increases to 2.1. It is concluded that these differences are very significant and design standards need to be revised to reflect these findings.

- It was also investigated if a uniform target reliability of $10^{-4} / \mathrm{annum}$ can be achieved by the introduction of an ALS condition, where the intact mooring system is required to satisfy environmental conditions with $10,000 \mathrm{yr}$ return period and FoS equal to unity. It is concluded that this objective is not met, although the probability of failure reduced significantly for the tropical cyclone environment. Hence, it is recommended to introduce this ALS check in addition to the ULS requirements.

- In addition, it was investigated what factor of safety is required for the NS environment if the target probability of failure is $10^{-5}$ /annum. This was done to directly compare the results of this study with those of the study performed by NorMoor Project. The results 
712 This work was supported by the ARC Industrial Transformation Research Hub for Offshore 713 Floating Facilities which is funded by the Australian Research Council, Woodside Energy, 714 Shell, Bureau Veritas and Lloyds Register (Grant No. IH140100012). The first and second 715 authors are also supported by the Shell offshore engineering initiative at the University of 716 Western Australia. These sources of support are gratefully acknowledged. 
722 [1] Longshore D. Encyclopedia of hurricanes, typhonons and cyclones. New York: Infobase

\section{Publishing; 2010.}

[2] Kidoura Y, Wada R, Waseda T. On the Aleatory and Epistemic Uncertainty of the Wave Resource Assesment in the North West Pacific. San Francisco: Proceedings of OMAE Conference; 2014.

[3] DNVGL. Offshore standard DNVGL-OS-E301: Position mooring. DNV GL AS; 2015.

[4] ISO. Specific requirements for offshore structures: Floating offshore structures- Part 1: Monohulls, semi-submersibles and spars. Geneva: International Standards; 2006.

[5] ISO. Specific requirements for offshore structures -Part 7:Stationkeeping systems for floating offshore structures and mobile offshore units ISO19901-7. Geneva: International Organization for Standardization; 2013.

[6] Neill K. Western Australia's domestic gas reservation policy: the elemental exonomics. Economic Papers. 2017;36:121-34.

[7] API. Recommended practice for design and analysis of station keeping systems for floating structures, API RP-2SK. Washington: American Petrolium Institute; 2005.

[8] Horte T, Okkenhaug S, Paulshus O. Mooring system calibration of the intact condition, ultimate limit state, ULS. OMAE Conference. Trondheim: ASME; 2017.

[9] Horte T, Okkenhaug S, Paulshus O. Mooring system calibration of the damaged condition, ALS. OMAE Conference. Trondheim: ASME; 2017.

[10] Okkenhaug S, Horte T, Paulshus O. Mooring system calibration for safe mooring system design in ULS and ALS. OMAE Conference. Trondheim: ASME; 2017.

[11] Stanisic D, Efthymoiu M, White D, Kimiaei M. Reliability of mooring lines and piles for a permanently manned vessel in a tropical cyclone environment. accepted in Applied Ocean Research (October 2018). 2018.

[12] Jonathan P, Ewans K, Flynn J. On the estimation of ocean engineering design contours. OMAE Conference. Vancouver: ASME; 2014.

[13] Heffernan JE, Tawn JA. A condotional approach for multivariate extreme values. Journal of the Royal Statistical Society:Series B (Statistical Methodology). 2004;66:497-546.

[14] Tromans PS, Vanderschuren L. Response-based design of floaters. OGP Workshop2001. p. 2-17. [15] van Zutphen H, Christou M. "Validation of FPSO LSM: A probability domain model applied to floating structures. Hague: Shell International Publications; 2009.

[16] Stanisic D, Efthymiou M, Kimiaei M, Zhao W. Design loads and long term distribution of mooring line response of a large weathervaning vessel in a tropical cyclone environment. Marine Structures. 2018;61:361-80.

[17] Stanisic D, Efthymiou M, Kimiaei M, Zhao W. Evaluation of conventional methods of establishing extreme mooring design loads. OMAE Conference. Trondheim: ASME; 2017.

[18] Muliawan MJ, Gao Z, Moan T. Application of the contour line method for estimating extreme responses in the mooring lines of a two-body floating wave energy converter. Journal of Offshore Mechanics and Arctic Engineering. 2013;135:031301--10.

[19] Haver S, Winterstein SR. Enviromental contour lines: A method for estimating long term extremes by short term analysis. Transactions- Society of Naval Architects and Marine Engineers. 2008;116:116-27.

[20] API. Specification for mooring chain-API specification 2F. Washington: American Petroleum Institute; 1997.

[21] DNVGL. Offshore mooring chain: DNVGL-OS-E302. DNVGL; 2015.

[22] Randolph M, Gourvenec S. Offshore geotechnical engineering. Oxon: Taylor \& Francis Group; 2011. 
[23] Frankenmolen SF, Erbrich CT, Fearon RE. Succesful installation of large suction caissons and driven piles in carbonate soils. London: Proceedings of the 8th International Conference-Offshore Site Investigation and Geotechnics; 2017.

771 [24] Erbrich C, Lam SY, Zhu H, Derache A, Sato A, Al-Showaiter A. Geotechnical design of anchor piles for Ichthys CPF and FPSO. London: Prceedings of the 8th International Conference- offshore Site Investigation and Geotechnics; 2017.

774 [25] Melchers RE. Structural reliability analysis and prediction. Chichester: John Wiley \& Sons; 1999.

775 [26] ISO. General principles on reliability for structures-ISO2394. Geneva: Interantional Organisation 776 for Standardisation; 2015. 